Mongolian Academy of Sciences
Mongolian Journal of Chemistry
Institute of Chemistry \& Chemical Technology

\title{
Bioactive phenolic acids from Scorzonera radiata Fisch.
}

\author{
N.Tsevegsuren ${ }^{1}$, P.Proksch ${ }^{2}$, Y.Wang ${ }^{3}$, G.Davaakhuu ${ }^{1}$ \\ ${ }^{1}$ National University of Mongolia, ${ }^{2}$ Heinrich-Heine University, Duesseldorf, ${ }^{3}$ Peking University
}

\begin{abstract}
Chromatographic separation of the crude extract obtained from the aerial parts of the Mongolian medicinal plant Scorzonera radiata yielded five new dihydrostilbenes [4], two new flavonoids, one new quinic acid derivative, as well as twenty known compounds including eight quinic acid derivatives, four flavonoids, two coumarins, five simple benzoic acids, and one monoterpene glycoside. We present here results on isolation and structural identification some active phenolic compounds from the Scorzonera radiata - eight quinic acid derivatives (quinic acid, 4,5-dicaffeoylquinic acid, 4,5-dicaffeoyl-epi-quinic acid, 3,5-dicaffeoylquinic acid, 3,5-dicaffeoyl-epi-quinic acid, chlorogenic acid, 5-p-coumaroylquinic acid (trans), 5-p-coumaroylquinic acid (cis)). Quinic acid derivatives exhibited antioxidative activity.
\end{abstract}

Keywords. Quinic acid, dicaffeoylquinic acid, dicaffeoyl-epi-quinic acid, chlorogenic acid, coumaroylquinic acid,

\section{Introduction}

Corzonera is a genus of the family Asteraceae that includes more than 150 species, which are distributed in the temperate zones of Eurasia. Eleven species of Scorzonera are found on the Mongolian plateau, two of which are endemic [2,5]. Scorzonera radiata Fisch. is a typical mesophyte and a perennial herbaceous rosette plant. All parts of the plant are used in Mongolian folk medicine for the treatment of poisonous ulcers, for fever caused by bacterial and viral infections, and for its diuretic and galactagogue properties [4].

No phytochemical studies have been reported for $S$. radiata, although other species of this genus have been studied extensively, resulting in the isolation of many active compounds including sesquiterpenes, lignans, neolignans, phenolic acids, triterpene derivatives, stilbene derivatives, dihydroisocoumarins, and flavonoids. Previously we have investigated S.divaricata and S.peseudodivaricata from Mongolian flora which were used in the Traditional Mongolian Medicine for cancer treatment and other diseases [9]. Aerial parts of Mongolian medicinal plant S.radiata from Mongolia were studied by us for first time.

The subject of this study was the isolation and structural elucidation of the secondary metabolites from medicinal plant S.radiata, followed by evaluation of their pharmocological potential. We have used various modern chromatographic techniques for separation and purification of natural products from the crude extract. The structures were unambiguously elucidated on the basis of one- and two-dimensional NMR and mass spectrometric data.

\section{Experimental \\ Isolation of secondary metabolites from Scorzonera radiata}

The air-dried, powdered plant material of S.radiata was extracted exhaustively by maceration with $\mathrm{MeOH}(3 \times 400 \mathrm{ml})$ at room temperature. The total extract was concentrated to dryness under vacuum. The concentrated solids were reconstituted with $100 \mathrm{ml}$ of $\mathrm{MeOH} / \mathrm{H}_{2} \mathrm{O}$ (3:7) and then partitioned successively with hexane $(5 \times 100$ 
$\mathrm{ml})$, EtOAc (5x100 ml), and $n-\mathrm{BuOH}(5 \times 100$ $\mathrm{ml})$ to give the hexane, EtOAc, $n-\mathrm{BuOH}$ and aqueous fractions.

Aliquot amounts of the EtOAc fractions of the $\mathrm{MeOH}$ extract derived from the aerial parts of S.radiata were separated by HP-20 resin $\mathrm{CC}$ with gradient elution using $\mathrm{H}_{2} \mathrm{O}$ and $\mathrm{MeOH}$ as solvents to afford compounds $\mathbf{1}$ $(19.3 \mathrm{mg})$ and $4(242.0 \mathrm{mg})$. Aliquot amounts of the $n-\mathrm{BuOH}$ fractions were separated by Sephadex LH-20 resin CC with gradient elution using $\mathrm{MeOH}$ as solvents to afford 15 fractions. Compounds 5 (103.2 $\mathrm{mg}$ ) and 6 (240.1 mg) were separated by Sephadex LH$20 \mathrm{CC}$ using $\mathrm{MeOH}$ as mobile phase. Compounds $\mathbf{2}(3.0 \mathrm{mg}), \mathbf{3}(3.1 \mathrm{mg}), \mathbf{7}$ (0.6 $\mathrm{mg})$, and $8(0.6 \mathrm{mg})$ were purified by semipreparative HPLC utilizing RP-18 as stationary phase and mixtures of $\mathrm{MeOH} / \mathrm{H}_{2} \mathrm{O}$ as solvent.

\section{Radical-scavenging activity by DPPH}

Qualitative analysis of radical-scavenging activity of the extracts and fractions was carried out by spraying the TLC plates after development in an appropriate solvent system (EtOAc/ $\left./ \mathrm{HCO}_{2} \mathrm{H} / \mathrm{H}_{2} \mathrm{O}, 85: 10: 5\right)$ with $1 \%$ 2,2diphenyl-1-picrylhydrazyl (DPPH) reagent. Active components were observed as yellow bands against a violet background.

\section{Results and Discussion}

Compoind 1. Quinic acid. Molecular formula: $\mathrm{C}_{7} \mathrm{H}_{12} \mathrm{O}_{6}$, molecular weight: 192.17. Compound $\mathbf{1}$ was isolated as colourless needles without any UV absorption. The ESI mass spectrum showed a negative pseudomolecular ion peak at $m / z$ 191. The ${ }^{1} \mathrm{H}$ NMR spectrum of $\mathbf{1}$ displayed three oxymethine protons at $\delta_{\mathrm{H}} 4.04,3.91$, and 3.45 , together with two pairs of $\mathrm{sp}^{3}$ methylene protons at $\delta_{\mathrm{H}} 1.95 / 1.86$ and $1.96 / 1.77$ for $\mathrm{H}_{2}-2$ and $\mathrm{H}_{2}-6$, respectively. By inspection of the ${ }^{13} \mathrm{C}$ NMR spectrum, these resonances were in agreement with three oxymethine resonances at $\delta_{\mathrm{C}} 67.4,70.8$, and 75.6; two $\mathrm{sp}^{3}$ methylenes at $\delta_{\mathrm{C}} 37.8$ and 41.1 ; an oxygenated quaternary carbon at $\delta_{\mathrm{C}} 77.5$; and a carboxyl resonance at $\delta_{\mathrm{C}} 181.8$, all of which were characteristic of quinic acid. Comparing the data of (-)-quinic acid with that of compound 1, both compounds (Table 1) were identical [1].

\begin{tabular}{lclcl}
\multicolumn{5}{c}{ Table 1. NMR spectroscopic data of compound $\mathbf{1}\left(\mathrm{D}_{2} \mathrm{O}, 500 \mathrm{MHz}\right)$} \\
\hline \multicolumn{4}{c}{ Quinic acid (DMSO) } & \multicolumn{3}{c}{ Compound 1 } \\
\hline Position & $\delta_{\mathrm{C}}$ & $\delta_{\mathrm{H}}$ (mult., $J$ in $\left.\mathrm{Hz}\right)$ & \multicolumn{1}{c}{$\delta_{\mathrm{C}}$} & \multicolumn{1}{c}{$\delta_{\mathrm{H}}($ mult., $J$ in Hz) } \\
\hline 1 & $74.7, \mathrm{qC}$ & & $77.5, \mathrm{qC}$ & \\
2 eq & $37.6, \mathrm{CH}_{2}$ & $1.7, \mathrm{dd}(13,3.3)$ & $37.8, \mathrm{CH}_{2}$ & $2.10, \mathrm{dd}(14.9,3.4)$ \\
$2 \mathrm{ax}$ & & $1.6, \mathrm{dd}(13,3.3)$ & & $2.02, \mathrm{dd}(14.8,3.6)$ \\
3 & $69.3, \mathrm{CH}$ & $3.8, \mathrm{td}(3.3,2.2)$ & $67.4, \mathrm{CH}$ & $4.20, \mathrm{ddd}(3.5,3.5,3.4)$ \\
4 & $74.8, \mathrm{CH}$ & $3.2, \mathrm{dd}(7.8,2.2)$ & $75.6, \mathrm{CH}$ & $3.60, \mathrm{dd}(9.3,3.3)$ \\
5 & $66.9, \mathrm{CH}$ & $3.7, \mathrm{td}(7.8,4)$ & $70.8, \mathrm{CH}$ & $4.07, \mathrm{ddd}(10.6,9.4,4.6)$ \\
6eq & $40.7, \mathrm{CH}_{2}$ & $1.8, \mathrm{dd}(13,4)$ & $41.1, \mathrm{CH}_{2}$ & $2.12, \mathrm{dd}(13.4,4.7)$ \\
6ax & & $1.7, \mathrm{dd}(13,7.8)$ & & $1.92, \mathrm{dd}(13.4,10.9)$ \\
7 & $175.8, \mathrm{qC}$ & & $181.8, \mathrm{qC}$ & \\
\hline
\end{tabular}

Compound 2. 4,5-dicaffeoylquinic acid. Molecular formula: $\mathrm{C}_{25} \mathrm{H}_{24} \mathrm{O}_{12}$, molecular weight: 516.45 .

Compound 2 was isolated as a yellowish amorphous solid $\left([\alpha]^{20}{ }_{\mathrm{D}}:-74^{0}\right)$ with UV absorbances at $\lambda_{\max } 219,244$, and $329 \mathrm{~nm}$. Its molecular weight 516 was deduced from the ESIMS spectrum. The ${ }^{1} \mathrm{H}$ NMR spectrum of 2 exhibited one quinic acid and two caffeoyl moieties. The assignments and the configuration of the quinic acid moiety were determined by analysis of the ${ }^{1} \mathrm{H}-{ }^{1} \mathrm{H}$ COSY and ROESY spectra. The proton resonances at $\delta_{\mathrm{H}} 5.09$ and 5.69 were assigned to $\mathrm{H}-4$ and H-5 respectively. Comparison of the ${ }^{1} \mathrm{H}$ NMR spectral data of compound $\mathbf{2}$ to those of quinic acid showed the downfield shift for $\mathrm{H}$ 4 by -1.49 ppm and for H-5 by -1.62 ppm, respectively, which implied that the attachments of the two caffeoyl units were at carbon 4 and 5. Due to above mentioned results, compound 2 was identified as 4,5dicaffeoylquinic acid [7].

Compound 3. 4,5-dicaffeoyl-epi-quinic acid. Molecular formula: $\mathrm{C}_{25} \mathrm{H}_{24} \mathrm{O}_{12}$, molecular weight: 516.45 .

Compound 3 was obtained as an amorphous solid. The molecular formula was determined as $\mathrm{C}_{25} \mathrm{H}_{24} \mathrm{O}_{12}$ from HRESIMS data $(\mathrm{m} / \mathrm{z}$ 517.1341 $[\mathrm{M}+\mathrm{H}]+$ ) (Figure 2). The UV spectrum of 3 (Figure 1) showed absorption maxima at 325, 243 and $218 \mathrm{~nm}$ which typical of a caffeic acid derivative.

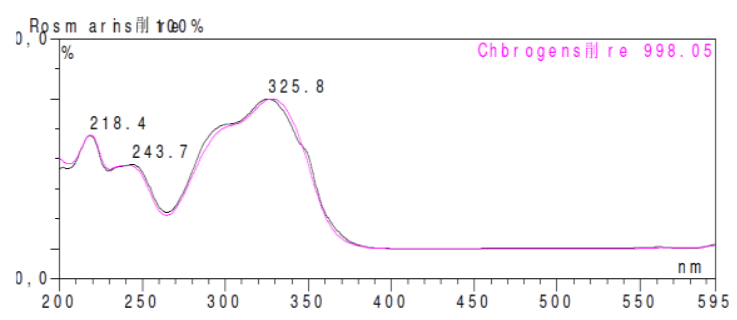

Figure 1. UV spectrum of compound 3 


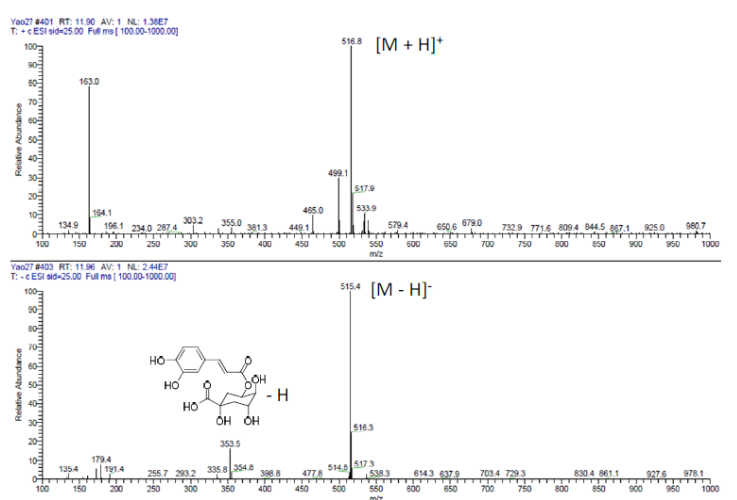

Figure 2. ESI-MS spectrum of compound $\mathbf{3}$

The ${ }^{1} \mathrm{H}$ NMR data were very similar to those of $\mathbf{3}$ for the caffeic acid moieties [7].

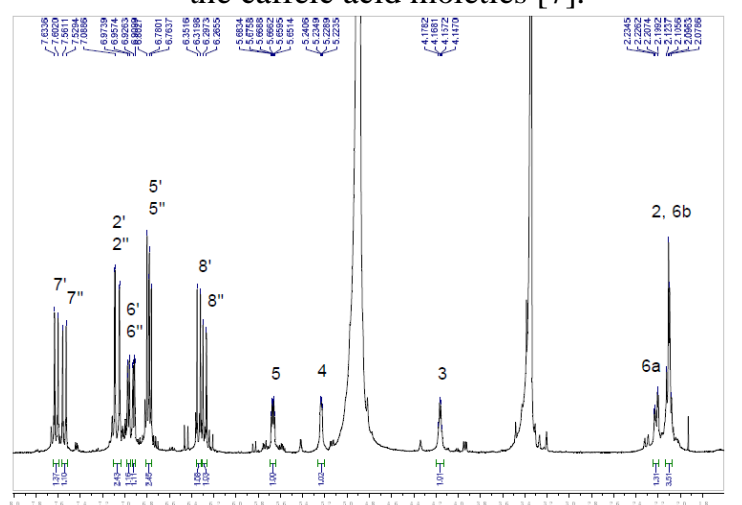

Figure 3. ${ }^{1} \mathrm{H}$ NMR spectrum of compound $\mathbf{3}$

The ${ }^{1} \mathrm{H}$ NMR spectrum of $\mathbf{3}$ (Figure 3 ) showed two pairs of doublets with coupling constants of $15.9 \mathrm{~Hz}$. In the aromatic region, resonances for two ABX systems $\left[\delta_{\mathrm{H}} 7.05(\mathrm{~d}\right.$, $J=2.1 \mathrm{~Hz}), 6.78(\mathrm{~d}, J=8.1 \mathrm{~Hz})$ and $6.92(\mathrm{dd}$, $J=8.1,2.1 \mathrm{~Hz})$; and $\delta_{\mathrm{H}} 7.09(\mathrm{~d}, J=2.2 \mathrm{~Hz})$, $6.80(\mathrm{~d}, J=8.2 \mathrm{~Hz})$ and $6.97(\mathrm{dd}, J=8.2,2.2$ $\mathrm{Hz}$ )] were observed, which assigned to two 1,3,4-trisubstituted phenyl units.

The assignments of signals further provided by analysis of ROESY spectrum of compound 3 (Figure 5). The protons at $\delta 7.05$ (H-2') and 7.09 (H-2"') gave ROESY cross-peaks with the olefinic protons at $\delta_{\mathrm{H}} 7.55\left(\mathrm{H}-7^{\prime}\right)$ and 7.62 (H-7'). The presence of the quinic acid moiety was indicated by ${ }^{1} \mathrm{H}$ NMR resonances of three oxymethine protons at $\delta_{\mathrm{H}} 5.67$ (ddd, $J$ $=8.6,4.1,3.3 \mathrm{~Hz}), 5.24(\mathrm{dd}, J=6.1,3.0 \mathrm{~Hz})$ and 4.16 (ddd, $J=5.6,5.4,5.3 \mathrm{~Hz}$ ), together with two pairs of $\mathrm{sp}^{3}$ methylene protons at $\delta_{\mathrm{H}}$ 2.22/2.10 and 2.11/2.08 for $\mathrm{H}_{2}-6$ and $\mathrm{H}_{2}-2$, respectively. All of these signals are characteristic to quinic acid unit.

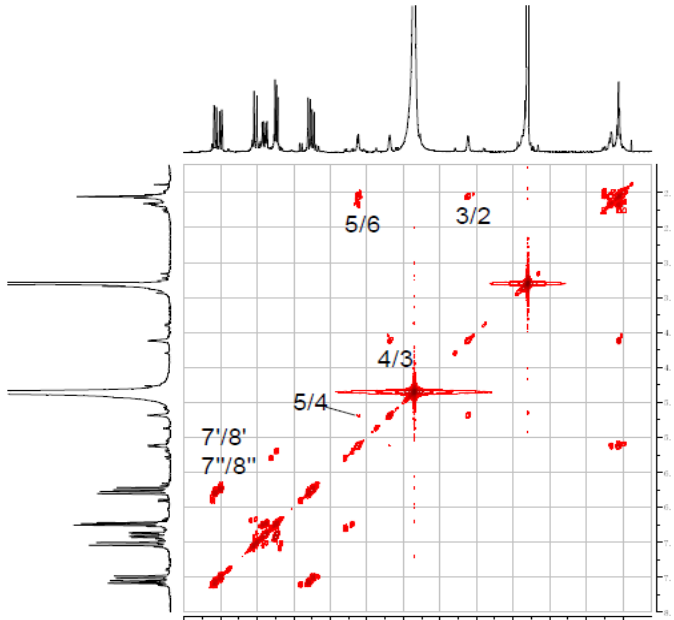

Figure 4. ${ }^{1} \mathrm{H}-{ }^{1} \mathrm{H}$ COSY spectrum of compound 3

The assignments of the protons in the quinic acid molecule were corroborated by analysis of the ${ }^{1} \mathrm{H}-{ }^{1} \mathrm{H}$ COSY (Figure 4) and ROESY spectra of $\mathbf{3}$.

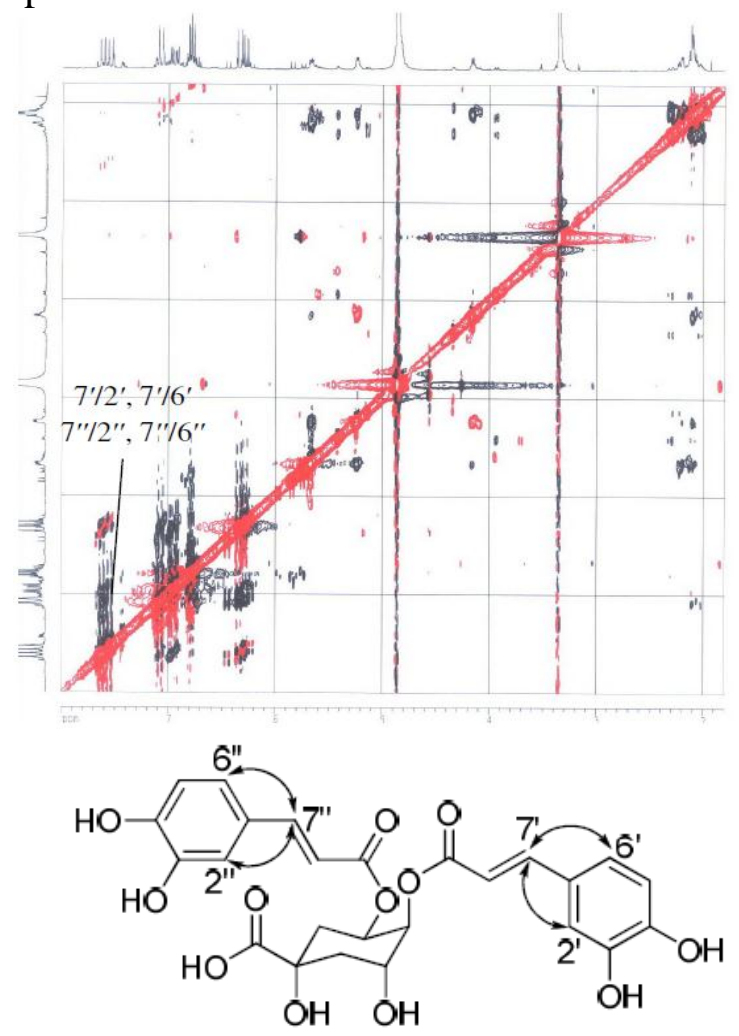

Figure 5. ROESY spectrum of compound $\mathbf{3}$

The attachments of the two caffeoyl moieties at C-4 and C-5 of quinic acid part were deduced from the HMBC correlation (Figure 6) of $\mathrm{H}-4$ and $\mathrm{H}-5$, with their ester carbonyl carbons (C-9' and C-9'') at $\delta_{\mathrm{C}}$ 168.3, respectively. 
The deshielded resonances of two oxymethine protons in the quinic acid nucleus at $\delta_{\mathrm{H}} 5.67$ (H-5) and $5.24(\mathrm{H}-4)$ implied acylation of the hydroxyl group at positions which earlier reported for other naturally occurring quinic acid derivatives [7]. From these observations, the structure of $\mathbf{3}$ was initially thought to be the known compound 2.

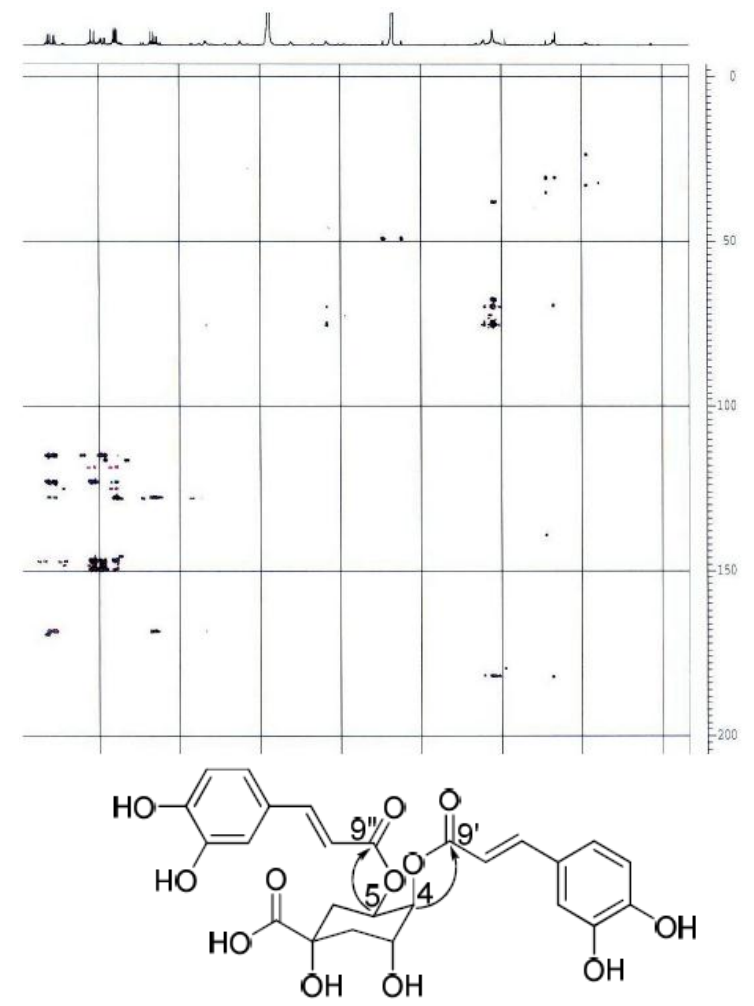

Figure 6. HMBC spectrum of compound 3

However, the ${ }^{1} \mathrm{H}$ NMR spectrum of $\mathbf{3}$ showed slightly but distinctly different peak patterns of the quinic acid unit compared to the known compound 2 [ $\delta_{\mathrm{H}-3} 4.29,(\mathrm{dt}, J=3.2,2.8 \mathrm{~Hz})$, $\delta_{\mathrm{H}-4} 5.09,(\mathrm{dd}, J=10.4,3.2 \mathrm{~Hz})$ and $\delta_{\mathrm{H}-5} 5.69$, $(\mathrm{dt}, J=6.6,10.4 \mathrm{~Hz})]$, which was also isolated from this plant. The structure of the known compound $\mathbf{2}$ had been ascertained by a detailed comparison of the physical and spectral data with those of the literature [7].

Thus, we assumed that compound $\mathbf{3}$ is a conformational isomer of $\mathbf{2}$. To elucidate the conformation of $\mathbf{3}$, comprehensive NMR studies were undertaken. Firstly, a ROESY experiment was carried out. Has not been detected clear ROESY cross-peaks from the oxymethine proton $\mathrm{H}-4(\delta 5.24)$ to any of the $\mathrm{sp}^{3}$ methylene protons $\mathrm{H}-2(\delta 2.11$ and 2.08$)$ or H-6 ( $\delta 2.22$ and 2.10). Moreover, the physical properties (solubility, optical rotation) of $\mathbf{3}$ were different from those of the known 2. Like other epi-quinic acid derivatives, $\mathbf{3}$ has limited solubility in methanol, while the known derivative is freely soluble in the same solvent. Conformational isomers of quinic acid have been investigated thoroughly, and three principal structures have been confirmed, namely (-)-quinic acid, (-)-epiquinic acid and (+)-quinic acid [3]. The negative optical rotation of 3 of $[\alpha]^{20}{ }_{D}:-32^{0}$ eliminates the probability of a (+)-quinic acid derivative. Taken together these data indicate According to NMR spectral data compound 3 contains the epi-isomer of quinic acid and is 4,5dicaffeoyl-epi-quinic acid (Table 2).

Table 2. NMR spectroscopic data of compound $3\left(\mathrm{CD}_{3} \mathrm{OD}, 600 \mathrm{MHz}\right)$

\begin{tabular}{|c|c|c|c|c|c|}
\hline $\begin{array}{l}\text { Posi } \\
\text { tion }\end{array}$ & $\delta_{\mathrm{C}}$ & $\delta_{\mathrm{H}}$ (mult., $J$ in $\mathrm{Hz}$ ) & $\cos Y$ & $\begin{array}{c}\text { ROES } \\
\mathrm{Y}\end{array}$ & HMBC \\
\hline 1 & $75.5, \mathrm{qC}$ & & & & \\
\hline $2 \mathrm{eq}$ & $38.0 \mathrm{CH}_{2}$ & $2.11, \mathrm{~m}^{\alpha}$ & 3 & & \\
\hline $2 \mathrm{ax}$ & $38.0 \mathrm{CH}_{2}$ & $2.08, \mathrm{dd}(13.1,5.3)$ & 3 & $6 \mathrm{ax}$ & \\
\hline $3 a x$ & $67.9, \mathrm{CH}$ & $4.16, \operatorname{ddd}(5.6,5.4,5.3)$ & 2eq, $2 \mathrm{ax}, 4$ & & $\mathrm{C} 1, \mathrm{C} 5$ \\
\hline $4 \mathrm{eq}$ & $72.8, \mathrm{CH}$ & $5.24, \mathrm{dd}(6.1,3.0)$ & 3,5 & & $\mathrm{C} 3, \mathrm{C} 9$ \\
\hline 5 eq & $70.0, \mathrm{CH}$ & $5.67, \operatorname{ddd}(8.6,4.1,3.3)$ & $4,6 \mathrm{eq}, 6 \mathrm{ax}$ & & $\mathrm{C} 1, \mathrm{C} 6, \mathrm{C} 9$ ", \\
\hline $6 \mathrm{eq}$ & $39.7, \mathrm{CH}_{2}$ & $2.22, \mathrm{dd}(13.2,4.1)$ & 5 & $2 \mathrm{ax}$ & \\
\hline $6 \mathrm{ax}$ & $39.7, \mathrm{CH}_{2}$ & $2.10, \mathrm{~m}^{a}$ & 5 & $2 \mathrm{ax}$ & \\
\hline 7 & $182.0, \mathrm{qC}$ & & & & \\
\hline 1 , & $127.8, \mathrm{qC}$ & & & & \\
\hline 2 , & $115.0, \mathrm{CH}$ & $7.09, \mathrm{~d}(2.2)$ & 6 , & & $\mathrm{C}^{\prime}, \mathrm{C} 6^{\prime}, \mathrm{C} 7^{\prime}$ \\
\hline 3 , & $146.7, \mathrm{qC}$ & & & & \\
\hline 4 , & $149.6, \mathrm{qC}$ & & & & \\
\hline 5 , & $116.5, \mathrm{CH}$ & $6.80, \mathrm{~d}(8.2)$ & 6 & & $\mathrm{C} 1^{\prime}, \mathrm{C} 3^{\prime}, \mathrm{C} 4$, \\
\hline 6 , & $123.1, \mathrm{CH}$ & $6.97, \mathrm{dd}(8.2,2.2)$ & $2^{\prime}, 5$, & & $\mathrm{C} 2, \mathrm{C}^{\prime}, \mathrm{C} 7$, \\
\hline 7, & $147.1, \mathrm{CH}$ & $7.62, \mathrm{~d}(15.9)$ & 8 & $2^{\prime}, 6$, & $\mathrm{C} 2, \mathrm{C} 6, \mathrm{C} 9$, \\
\hline 8 , & $115.1, \mathrm{CH}$ & $6.34, \mathrm{~d}(15.9)$ & 7 & & $\mathrm{C} 1, \mathrm{C} 9$, \\
\hline 9 , & $168.3, \mathrm{qC}$ & & & & \\
\hline 1 ," & $127.8, \mathrm{qC}$ & & & & \\
\hline 2, & $115.0, \mathrm{CH}$ & $7.05, \mathrm{~d}(2.1)$ & 6", & & $\mathrm{C} 4$ ",, $\mathrm{C} 6$ ", $\mathrm{C} 7$ ", \\
\hline 3, & $146.7, \mathrm{qC}$ & & & & \\
\hline 4 ", & $149.6, \mathrm{qC}$ & & & & \\
\hline $5 "$ & $116.5, \mathrm{CH}$ & $6.78, \mathrm{~d}(8.1)$ & 6, & & $\mathrm{C} 1$ ", $\mathrm{C} 3$ ",, $\mathrm{C} 4$ "' \\
\hline 6 ," & $123.1, \mathrm{CH}$ & $6.92, \mathrm{dd}(8.1,2.1)$ & $2,, 5$, & & $\mathrm{C} 2,, \mathrm{C} 4,, \mathrm{C} 7$, \\
\hline 7, & $147.1, \mathrm{CH}$ & $7.55, \mathrm{~d}(15.9)$ & 8, & $2,, 6 "$, & $\mathrm{C} 2,, \mathrm{C} 6,, \mathrm{C} 9$, \\
\hline $8 "$, & $115.1, \mathrm{CH}$ & $6.28, \mathrm{~d}(15.9)$ & $7^{\prime}$, & & $\mathrm{C} 1$ ", $\mathrm{C} 9$, \\
\hline 9, & $168.3, \mathrm{gC}$ & & & & \\
\hline
\end{tabular}

$a^{a}$ Overlapped signals assigned by ${ }^{1} \mathrm{H}^{-1} \mathrm{H}$ COSY, HMBC, and HMQC spectra without designating multiplicity.

Compound 4. 3,5-dicaffeoylquinic acid. Molecular formula: $\mathrm{C}_{25} \mathrm{H}_{24} \mathrm{O}_{12}$, molecular weight: 516.45 .

Compound 4 was obtained as a yellowish amorphous solid, and its molecular weight was determined to be 516 by ESIMS ion peaks at $m / z 517[\mathrm{M}+\mathrm{H}]+$ and $m / z 515[\mathrm{M}-$ $\mathrm{H}]-$. Its UV spectrum displayed maximal absorption at 220, 243, and $328 \mathrm{~nm}$ indicating the presence of caffeic acid moiety. The ${ }^{1} \mathrm{H}$ and ${ }^{13} \mathrm{C}$ NMR spectra of 4 showed two methylenes, three oxygenated protons and a carbonyl carbon at $\delta 177.3$, which were assigned for a qunic acid unit. In addition, the presence of two trans-caffeoyl groups was indicated by the observation of two $\mathrm{ABX}$ systems and two trans-olefinic protons. The 
above spectral data were consistent with those of 3,5-dicaffeoylquinic acid [7,10]. Thus, compound 4 was concluded to be $\mathbf{3 , 5}$ dicaffeoylquinic acid.

Compound 5. 3,5-dicaffeoyl-epi-quinic acid. Molecular formula: $\mathrm{C}_{25} \mathrm{H}_{24} \mathrm{O}_{12}$, molecular weight: 516.45 .

Compound 5 was obtained as a yellowish amorphous solid $\left([\alpha]^{20}{ }_{\mathrm{D}}:-113.0^{0}\right)$ with a UV maximal absorption at 218, 243, and $329 \mathrm{~nm}$. The molecular weight 516 was established by ESIMS. The ${ }^{1} \mathrm{H}$ and ${ }^{13} \mathrm{C}$ NMR spectra of 5 exhibited signals for two caffeic acids and a quinic acid moiety indicating a structure similar to that of $\mathbf{4}$ except for the quinic acid moiety. In the ROESY spectrum, the proton at $\delta 3.89(\mathrm{H}-4)$ gave two cross-peaks with the protons at $\delta 5.53(\mathrm{H}-3)$ and $\delta 5.37(\mathrm{H}-5)$, respectively. This observation indicated that the proton $\mathrm{H}-4$ is in axial orientation. Compound 5 was concluded to be as 3,5dicaffeoyl-epi-quinic acid which is an epimer of 4 [3].

Compound 6. Chlorogenic acid. Molecular formula: $\mathrm{C}_{16} \mathrm{H}_{18} \mathrm{O}_{9}$, Molecular weight: 354.31.

Compound 6 was isolated as an amorphous solid. It had UV absorption at $\lambda_{\max } 218,242$, and $326 \mathrm{~nm}$, which were typical for caffeic acid derivatives. The molecular weight of $\mathbf{6}$ was determined as 354 by ion peaks found in ESIMS spectrum at $\mathrm{m} / z 355[\mathrm{M}+\mathrm{H}]+$ and $\mathrm{m} / \mathrm{z} 353[\mathrm{M}-\mathrm{H}]-$. The aliphatic region of the ${ }^{1} \mathrm{H}$ NMR spectrum was comparable to that of compound $\mathbf{1}$, however in the aromatic region, resonances for an $\mathrm{ABX}$ system at $\delta_{\mathrm{H}} 7.04(\mathrm{~d}$, $J=2.2 \mathrm{~Hz}), 6.76(\mathrm{~d}, J=8.2 \mathrm{~Hz})$ and $6.94(\mathrm{dd}$, $J=8.2,2.2 \mathrm{~Hz}$ ), as well as a pair of doublet with coupling constants of $15.8 \mathrm{~Hz}$ were observed. Compound $\mathbf{6}$ was identified as chlorogenic acid by comparing of their ${ }^{1} \mathrm{H}$ NMR and MS data with those of reference [7].

Compound 7. 5-p-coumaroylquinic acid (trans). Molecular formula: $\mathrm{C}_{16} \mathrm{H}_{18} \mathrm{O}_{8}$, molecular weight: 338.31 .

Compound 7 was isolated as an amorphous solid and had a molecular weight of 338 . It had UV absorbances at $\lambda_{\max } 205,210$, and
$308 \mathrm{~nm}$ indicating the presence of $p$-coumaric acid moiety as the sole chromophore. In the ${ }^{1} \mathrm{H}$ NMR spectrum of $\mathbf{7}$, the olefinic protons showed a $J$ value of $16.0 \mathrm{~Hz}$ indicating the $p$ coumaric acid moiety with transconfiguration. Corroborating ${ }^{1} \mathrm{H} \quad \mathrm{NMR}$ resonances with ${ }^{1} \mathrm{H}-{ }^{1} \mathrm{H}$ COSY spectrum of 7 , revealed the presence of a quinic acid aliphatic ring system. The ${ }^{1} \mathrm{H}$ NMR data of 7 agreed with that of reference compound, thus $\mathbf{7}$ was assigned as 5-p-coumaroylquinic acid (trans) [6].

\section{Compound 8. 5-p-coumaroylquinic acid} (cis). Molecular formula: $\mathrm{C}_{16} \mathrm{H}_{18} \mathrm{O}_{8}$, molecular weight: 338.31 .

Compound $\mathbf{8}$ was obtained as an amorphous solid. It had the same molecular weight and UV absorbances as compound 7. Compound 8 was further determined as 5- $p$ coumaroylquinic acid (cis). In compound $\mathbf{8}$ olefinic protons had smaller coupling constant $J(12.6 \mathrm{~Hz})$ compared with the $J$ value (16.0 $\mathrm{Hz}$ ) in compound 7. Due to above observations and comparison with literature data the compound 8 was determined as 5-pcoumaroylquinic acid (cis) [6].

The name and structure of compounds that have been isolated and structurally elucidated from S.radiata are summarized in Table 3.

Table 3. List of isolated compounds from S.radiata

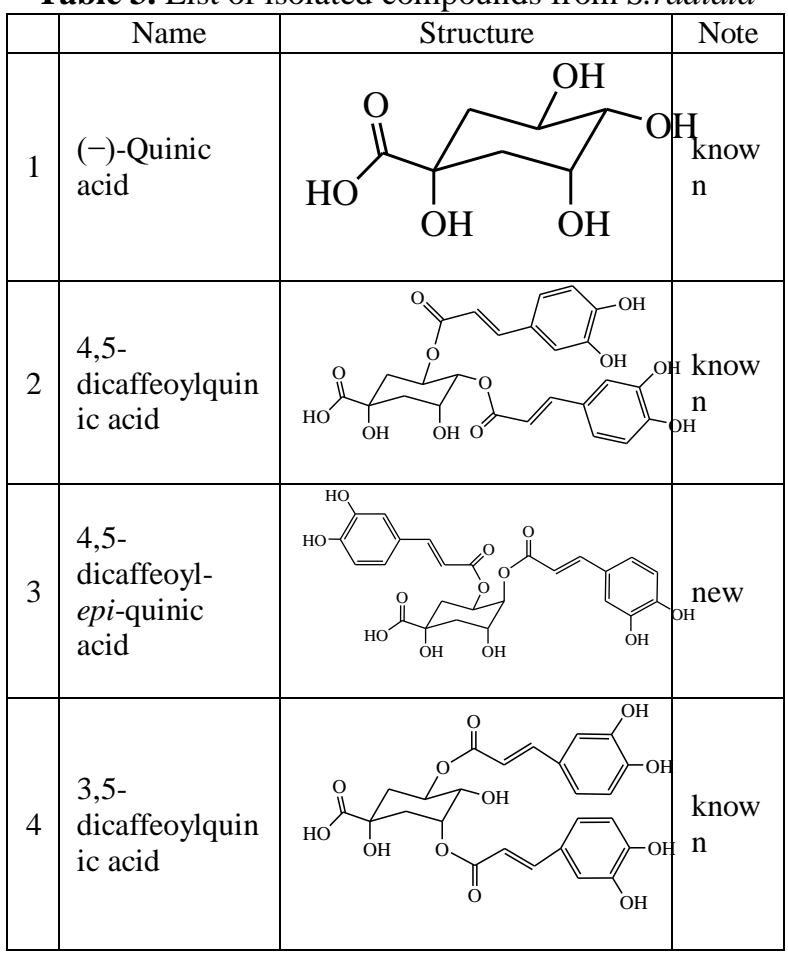




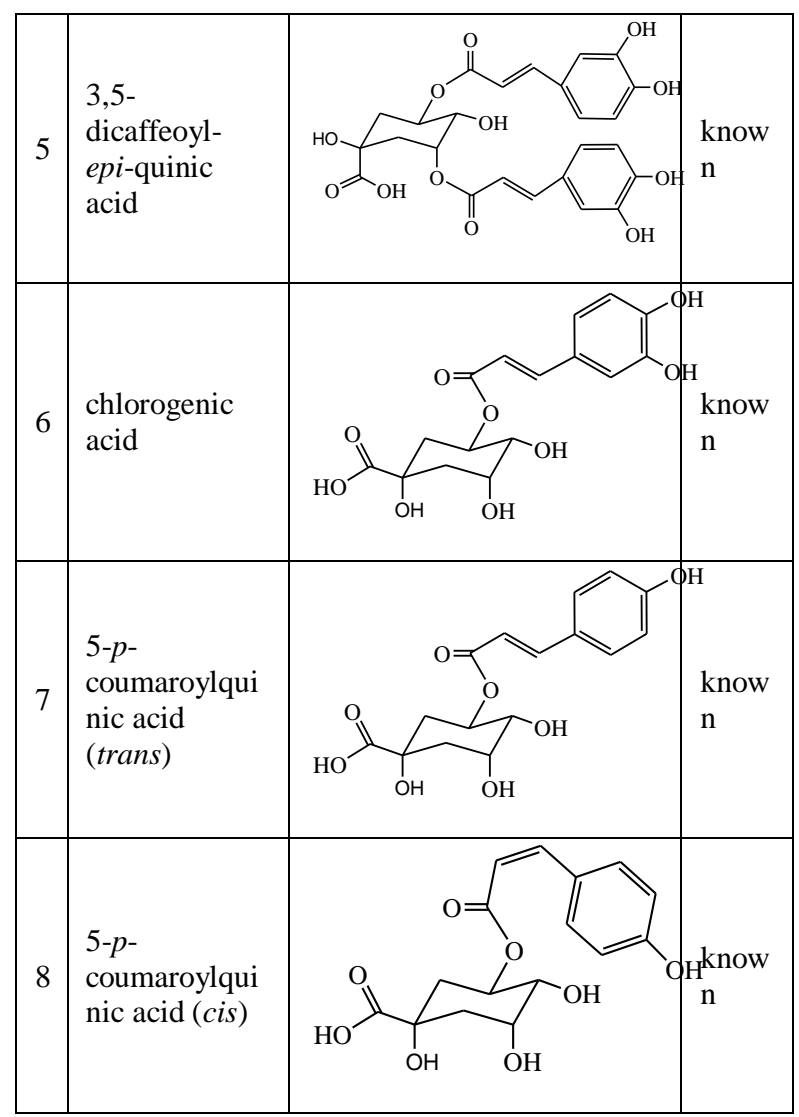

In this study, two unusual epiquinic acid derivatives were obtained including a new one. Due to the fact that epimers of quinic acid derivatives are studied rarely, the biosynthetic pathway has never been published.

The caffeoyl quinic acid congeners were considerably more active than 5-pcoumaroylquinic acid, since phenolic compounds exhibits vicinal $\mathrm{OH}$ groups have a higher radical scavenging activity than monohydroxylated isomers ( $p$-coumaric acid) [8]. The antioxidant efficiency of chlorogenic acid was found to be weaker than those of the dicaffeoylquinic acids. 4,5-dicaffeoyl-epiquinic acid (3) and 3,5-dicaffeoyl-epi-quinic acid (5) exhibited slightly stronger antioxidant activities compared to 4,5dicaffeoylquinic acid (2) and 3,5dicaffeoylquinic acid (4), respectively.

\section{Conclusions}

We present here results on isolation and structural identification of some active phenolic compounds from the Mongolian medicinal plant S.radiata - one new quinic acid derivative (4,5-dicaffeoyl-epi-quinic acid), as well as seven known quinic acid derivatives (quinic acid, 4,5- dicaffeoylquinic acid, 3,5-dicaffeoylquinic acid, 3,5dicaffeoyl-epi-quinic acid, chlorogenic acid, 5- $p$-coumaroylquinic acid (trans), 5- $p$ coumaroylquinic acid (cis)).

The structures were unambiguously elucidated on the basis of one- and twodimensional NMR and mass spectrometric data.

\section{References}

1. Flores-Parra.A., Gutiérrez-Avella.D.M., Contreras.R. and Khuong-Huu.F. (1989). ${ }^{13} \mathrm{C}$ and ${ }^{1} \mathrm{H}$ NMR investigations of quinic acid derivatives: Complete spectral assignment and elucidation of preferred conformations. Magnetic Resonance in Chemistry, 27(6), 544 - 555.

2. Grubov.V.I. Key to the Vascular Plants of Mongolia; Nauka: Leningrad, 1982; pp 263-264.

3. Kim.H.J. and Lee.Y.S. (2005). Identification of new dicaffeoylquinic acids from Chrysanthemum morifolium and their antioxidant activities. Planta Med, 71(9), 871-876.

4. Ligaa,U. Medicinal Plants from Mongolia Used in Mongolian Traditional Medicine; KS A Press: Ulaanbaatar, 1996; p 337.

5. Liu,G.X., ZHao,Y.Z. and Xu,J. (2001). Study on Classification and Ecology Geographical Distribution of Plants from the Genus Scorzonera in the Mongolian Plateau. Grassland of China, 23(2), 12 18.

6. Lu.Y., Sun.Y., Foo.L.Y., McNabb.W.C. and Molan.A.L. (2000). Phenolic glycosides of forage legume Onobrychis viciifolia. Phytochemistry, 55(1), 67-75.

7. Pauli.G.F., Poetsch.F. and Nahrstedt.A. (1998). Structure assignment of natural quinic acid derivatives using proton nuclear magnetic resonance techniques. Phytochemical Analysis, 9(4), 177-185.

8. Rice-Evans,C.A., Miller,N.J. and Paganga,G. (1996). Structure-antioxidant activity relationships of flavonoids and phenolic acids. Free Radic Biol Med, 20(7), 933-956.

9. Tsevegsuren.N., Edrada.R., Lin.W., Ebel.R., Torre.C., Ortlepp.S., Wray.V. and Proksch.P. (2007). Biologically active 
natural products from Mongolian medicinal plants Scorzonera divaricata and Scorzonera pseudodivaricata. J Nat Prod, 70(6), 962-967.
10. Wald.B., Wray.V., Galensa.R. and Herrmann.K. (1989). Malonated Flavonol Glycosides and 3,5-Dicaffeoylquinic acid from pears. Phytochemistry, 28(2), 663664. 